\title{
Consistency-based algorithms to estimate missing elements for uncertain 2-tuple linguistic preference relations
}

\author{
Zhen Zhang, Chonghui Guo* \\ Institute of Systems Engineering, Dalian University of Technology, Dalian, 116024,China \\ E-mail:zhangzhen@mail.dlut.edu.cn; guochonghui@tsinghua.org.cn
}

Received 5 April 2013

Accepted 8 August 2013

\begin{abstract}
For actual decision making problems, decision makers sometimes may have difficulty to provide all the preference information over alternatives through pairwise comparisons. In this paper, we focus on estimating missing elements for an incomplete uncertain 2-tuple linguistic preference relation. First, the additive consistency of an uncertain 2-tuple linguistic preference relation is defined. Based on the defined additive consistency, we define acceptable incomplete uncertain 2-tuple linguistic preference relation and propose two new algorithms, including an iterative algorithm and an optimization-based algorithm to estimate the missing elements for an uncertain 2-tuple linguistic preference relation. Finally, some numerical examples are presented to illustrate the applicability of the two algorithms.
\end{abstract}

Keywords: uncertain linguistic preference relation; 2-tuple linguistic; incomplete preference relation; additive consistency; goal programming

\section{Introduction}

Preference relation is a useful tool for decision makers to express their preferences on alternatives or criteria by pairwise comparisons. In the last decades, different types of preference relations have been developed ${ }^{34}$, such as multiplicative preference relation ${ }^{12,20}$, fuzzy preference relation ${ }^{21,28}$, linguistic preference relation $9,13,23,27$, uncertain preference relation $17,29,31$ and intuitionistic preference relation 33,35 .

For actual decision making problems, decision makers usually provide incomplete preference relations. This may be due to time pressure, lack of knowledge, and their limited expertise related with problem domain ${ }^{8,13,32}$. It may be also because the number of alternatives is too large, or when deci- sion makers want to skip some direct critical comparisons between alternatives ${ }^{10}$. Up to now, decision making with incomplete preference relations has received more and more attention. One way to deal with incomplete preference relations is to estimate the missing elements based on the consistency of preference relations, and some authors have proposed different methods to estimate the missing elements and applied them into group decision making with incomplete preference relations $1,2,3,4,8,30$. For instance, $\mathrm{Xu}^{30}$ investigated group decision making with incomplete linguistic preference relations and presented an approach to estimating the missing elements. Based on the additive consistency of fuzzy preference relations, Herrera-Viedma et al. ${ }^{15}$ and Fedrizzi et al. ${ }^{10}$ proposed two methods to estimate the missing elements for a fuzzy preference relation.

${ }^{*}$ Corresponding author. 
In a later work, Chiclana et al. ${ }^{6}$ analyzed the two methods and pointed out that the two methods are very similar and can be considered complementary rather than competitors. Chiclana et al. ${ }^{7,8} \mathrm{de}-$ fined the U-consistency measure for a fuzzy preference relation and proposed a U-consistency based method to estimate the missing elements for an incomplete fuzzy preference relation. Alonso et al. 2 presented a procedure to estimate missing preference values when dealing with pairwise comparison and heterogeneous information, which can be applied to incomplete fuzzy, multiplicative, intervalvalued, and linguistic preference relations. Alonso et al. ${ }^{1}$ proposed a consistency-based procedure to estimate missing preference values when dealing with incomplete fuzzy linguistic preference relation$\mathrm{s}$ assessed using a 2-tuple fuzzy linguistic approach. Alonso et al. ${ }^{3}$ presented an implemented web based consensus support system that is able to help the moderator in a consensus process where experts are allowed to provide preferences using multiple type$\mathrm{s}$ (fuzzy, linguistic and multi-granular linguistic) of incomplete preference relations. In order to manage the consensus in group decision making under an unbalanced fuzzy linguistic context with incomplete information, Cabrerizo et al. ${ }^{4}$ presented a consensus model, part of which is an iterative procedure using consistency measures to estimate the incomplete information. Xia et al. ${ }^{25}$ defined the multiplicative consistency for a linguistic preference relation and proposed a method to estimate the missing elements for an incomplete linguistic preference relation.

However, most of the previous work focuses on dealing with incomplete accurate preference relations. When uncertain preference relations (including uncertain multiplicative preference relation, uncertain fuzzy preference relation and uncertain linguistic preference relation) are provided, these approaches may not work. In recent years, some work has been conducted to deal with incomplete uncertain preference relations. For instance, Genç et al. ${ }^{11}$ investigated the issue of consistency, missing values, and derivation of the priority of interval fuzzy preference relations, gave a method to check whether an interval fuzzy preference relation is consistent or not, and developed two approaches to estimate the missing elements. Xia and $\mathrm{Xu}^{24}$ defined the perfec$t$ multiplicative consistency of interval fuzzy preference relations, based on which they developed an algorithm to estimate missing elements for incomplete interval fuzzy preference relations. Liu ${ }^{16}$ addressed the consistency of interval multiplicative preference relations, based on which Liu et al. ${ }^{18}$ developed a goal programming model to complement incomplete preference relations. Zhang et al. ${ }^{35}$ defined 2tuple intuitionistic fuzzy linguistic preference relation and proposed an algorithm to estimate the missing elements for an incomplete preference relation.

As surveyed above, some work has been conducted to estimate the missing elements for incomplete uncertain preference relations. However, in the real world decision makers may express their preference information using uncertain linguistic variables and construct uncertain linguistic preference relations due to their vague knowledge about the degree of preference of one alternative over another ${ }^{31}$. Therefore, preference relations with uncertain linguistic variables have received more and more attentions in recent years. For instance, $\mathrm{Xu}^{31}$ introduced some uncertain linguistic aggregation operators and developed a direct approach to group decision making with uncertain additive linguistic preference relations without loss of information. Chen and Lee ${ }^{5}$ presented a new method for dealing with fuzzy group decision making problems with uncertain linguistic preference relations by defining the uncertain linguistic labels ordered weighted average operator. Tapia García et al. ${ }^{22}$ presented a consensus model for group decision making problems in which the experts use linguistic uncertain preference relations based on two consensus criteria and the concept of coincidence among preferences. $\mathrm{Xu}$ and $\mathrm{Wu}^{26}$ developed an approach to solve consensus problems when experts' preference information is given by uncertain linguistic preference relations. However, to the best of our knowledge, there is little research focusing on the consistency problem of uncertain linguistic preference relations, which is an important issue for decision making with preference relations. Moreover, there may be situations that the elements of an uncertain linguistic preference relation are missing due to the aforementioned reason- 
s. Thus an interesting problem may be how to estimate the missing elements for an uncertain linguistic preference relation. In this paper, we will focus on dealing with the aforementioned problems. The main contributions of this paper are twofold. First, we present some theories about the additive consistency of uncertain 2-tuple linguistic preference relations. Afterwards, based on the theories we define the acceptable incomplete uncertain 2-tuple linguistic preference relation and develop two algorithms to estimate the missing elements. One is an iterative algorithm, and the other is an optimization modelbased algorithm which can maximize the consistency of the uncertain 2-tuple linguistic preference relation. By using the two algorithms, the missing elements of an incomplete uncertain 2-tuple linguistic preference relation can be estimated.

The rest of this paper is organized as follows. In the next section, we review some related work of the 2-tuple linguistic representation model and the uncertain 2-tuple linguistic preference relation. After that, we define the additive consistency of the uncertain 2-tuple linguistic preference relation in section 3. In section 4, we propose two estimation algorithms for incomplete uncertain 2-tuple linguistic preference relations. Afterwards, some numerical examples are presented to illustrate the proposed algorithms in section 5. Finally, some discussions and conclusions are provided in section 6 .

\section{Preliminaries}

In this section, we review some related work of the uncertain 2-tuple linguistic preference relation. First, we give a brief description of the 2-tuple linguistic representation model introduced by Herrera and Martínez ${ }^{14}$.

\subsection{2-tuple linguistic representation model}

Let $S=\left\{s_{0}, s_{1}, \ldots, s_{g}\right\}$ denote a linguistic term set with odd cardinality, the element $s_{i}$ of which represents the $i$ th linguistic term in $S$, and $g+1$ is the cardinality of the linguistic term set $S$. The linguistic term set should satisfy the following characteristics 13,14 :
(1) The set is ordered: $s_{i}>s_{j}$, if $i>j$;

(2) There is a negation operator: $\operatorname{Neg}\left(s_{i}\right)=s_{j}$, such that $j=g-i$;

(3) Maximization operator: $\max \left(s_{i}, s_{j}\right)=s_{i}$, if $s_{i} \geqslant s_{j}$

(4) Minimization operator: $\min \left(s_{i}, s_{j}\right)=s_{i}$, if $s_{i} \leqslant s_{j}$.

In order to compute with words without loss of information, Herrera and Martínez ${ }^{14}$ proposed the 2-tuple linguistic representation model based on the concept of symbolic translation. The model uses a 2-tuple $\left(s_{k}, \boldsymbol{\alpha}\right)$ to represent linguistic information, where $s_{k}$ is a linguistic term which belongs to the predefined linguistic term set, $\alpha$ denotes the symbolic translation, and $\alpha \in[-0.5,0.5)$. Specifically, the 2-tuple linguistic representation model can be defined as follows.

Definition 1. ${ }^{14}$ Let $S=\left\{s_{0}, s_{1}, \ldots, s_{g}\right\}$ be a linguistic term set and $\beta \in[0, g]$ be a value representing the result of a symbolic aggregation operation, then the 2-tuple that expresses the equivalent information to $\beta$ is obtained with the following function:

$$
\begin{aligned}
& \Delta:[0, g] \rightarrow S \times[-0.5,0.5) \\
& \Delta(\beta)=\left(s_{k}, \alpha\right),
\end{aligned}
$$

with $k=\operatorname{round}(\beta), \alpha=\beta-k$, where "round( $(\cdot)$ " is the usual round operation, $s_{k}$ has the closest index label to $\beta$, and $\alpha$ is the value of symbolic translation.

Definition 2. ${ }^{14}$ Let $S=\left\{s_{0}, s_{1}, \ldots, s_{g}\right\}$ be a linguistic term set and $\left(s_{k}, \alpha\right)$ be a 2-tuple, there exists a function $\Delta^{-1}$, which can transform a 2-tuple into its equivalent numerical value $\beta \in[0, g]$. The transformation function can be defined as

$$
\begin{aligned}
& \Delta^{-1}: S \times[-0.5,0.5) \rightarrow[0, g] \\
& \Delta^{-1}\left(s_{k}, \alpha\right)=k+\alpha=\beta .
\end{aligned}
$$

Based on the above definitions, a linguistic term can be considered as a 2-tuple linguistic by adding a value 0 to it as symbolic translation, i.e. $s_{k} \in S \Rightarrow$ $\left(s_{k}, 0\right)$. In what follows, we will use the 2-tuple linguistic representation instead of linguistic terms. 


\subsection{Uncertain 2-tuple linguistic preference relation}

Definition 3. ${ }^{1}$ Let $S=\left\{s_{0}, s_{1}, \ldots, s_{g}\right\}$ be a linguistic term set with odd cardinality, then a matrix $P=\left(p_{i k}\right)_{n \times n}$ is called a 2-tuple linguistic preference relation if $\Delta^{-1}\left(p_{i k}\right)+\Delta^{-1}\left(p_{k i}\right)=g, p_{i i}=$ $\left(s_{g / 2}, 0\right)$, where $p_{i k}$ indicates the linguistic preference degree of the alternative $x_{i}$ over $x_{k}$, and $p_{i k} \in$ $S \times[-0.5,0.5), i, k \in N=\{1,2, \ldots, n\}$.

Definition 4. ${ }^{1}$ A 2-tuple linguistic preference relation $P=\left(p_{i k}\right)_{n \times n}$ is called additive consistent if the following additive transitivity is satisfied:

$p_{i k}=\Delta\left(\Delta^{-1}\left(p_{i j}\right)+\Delta^{-1}\left(p_{j k}\right)-g / 2\right), i, j, k \in N$.

Lemma 1. Let $S$ be a linguistic term set and $P=$ $\left(p_{i k}\right)_{n \times n}$ be a 2 -tuple linguistic preference relation, where $p_{i k} \in S \times[-0.5,0.5), i, k \in N$. Then the following statements are equivalent:

(i) $p_{i k}=\Delta\left(\Delta^{-1}\left(p_{i j}\right)+\Delta^{-1}\left(p_{j k}\right)-g / 2\right), i, j, k \in N$;

(ii) $p_{i k}=\Delta\left(\Delta^{-1}\left(p_{i j}\right)+\Delta^{-1}\left(p_{j k}\right)-g / 2\right), i, j, k \in N$ and $i<j<k$.

The proof of Lemma 1 is provided in Appendix A.

Based on the definitions of uncertain additive linguistic preference relation ${ }^{31}$ and 2-tuple linguistic preference relation ${ }^{1}$, we give the definition of the uncertain 2-tuple linguistic preference relation.

Definition 5. Let $S=\left\{s_{0}, s_{1}, \ldots, s_{g}\right\}$ be a linguistic term set with odd cardinality, then a matrix $L=\left(l_{i k}\right)_{n \times n}$ is called an uncertain 2-tuple linguistic preference relation if $l_{i k}=\left[l_{i k}^{-}, l_{i k}^{+}\right], l_{i k}^{+} \geqslant l_{i k}^{-}$, $\Delta^{-1}\left(l_{i k}^{-}\right)+\Delta^{-1}\left(l_{k i}^{+}\right)=\Delta^{-1}\left(l_{i k}^{+}\right)+\Delta^{-1}\left(l_{k i}^{-}\right)=g, l_{i i}^{+}=$ $l_{i i}^{-}=\left(s_{g / 2}, 0\right)$, where $l_{i k}$ indicates the interval-valued linguistic preference degree of the alternative $x_{i}$ over $x_{k}$, and $l_{i k}^{-}, l_{i k}^{+} \in S \times[-0.5,0.5), i, k \in N$.

\section{Additive consistency of uncertain 2-tuple linguistic preference relation}

In this section, we investigate the additive consistency of uncertain 2-tuple linguistic preference relations. Motivated by the idea of Ref. 17, we decompose an uncertain 2-tuple linguistic preference relation $L$ into two 2-tuple linguistic preference relations as follows.

Let $Q=\left(q_{i k}\right)_{n \times n}$ and $T=\left(t_{i k}\right)_{n \times n}$ be two 2-tuple linguistic preference relations with

$q_{i k}=\left\{\begin{array}{ll}l_{i k}^{+}, & i<k \\ \left(s_{g / 2}, 0\right), & i=k \\ l_{i k}^{-}, & i>k\end{array}, t_{i k}=\left\{\begin{array}{ll}l_{i k}^{-}, & i<k \\ \left(s_{g / 2}, 0\right), & i=k \\ l_{i k}^{+}, & i>k\end{array}\right.\right.$.

It is obvious that $Q$ and $T$ are two reciprocal 2tuple linguistic preference relations constructed by the boundary values of $L$. Let $C(\alpha)=\left(c_{i k}(\alpha)\right)_{n \times n}$ with $c_{i k}(\alpha)=\Delta\left(\alpha \Delta^{-1}\left(q_{i k}\right)+(1-\alpha) \Delta^{-1}\left(t_{i k}\right)\right), \alpha \in$ $[0,1], i, k \in N$, then we can easily have the following theorem.

Theorem 1. Let L be an uncertain 2-tuple linguistic preference relation, then we have

(1) $C(1)=Q, C(0)=T$;

(2) $c_{i k}(\alpha) \in\left[l_{i k}^{-}, l_{i k}^{+}\right], \forall \alpha \in[0,1], i, k \in N$;

(3) $C(\alpha)$ is a reciprocal 2-tuple linguistic preference relation, $\forall \alpha \in[0,1]$. A.

The proof of Theorem 1 is provided in Appendix

According to Theorem 1, we can find that an uncertain 2-tuple linguistic preference relation $L$ can be considered as a collection of several 2-tuple linguistic preference relations constructed by its decomposed 2-tuple linguistic preference relations $Q$ and $T$. Thus it is intuitive that if all the $C(\alpha), \alpha \in[0,1]$ are additive consistent, then the uncertain 2-tuple linguistic preference relation $L$ is additive consistent. The following theorem can guarantee the additive consistency of $C(\alpha), \alpha \in[0,1]$.

Theorem 2. For an uncertain 2-tuple linguistic preference relation $L$, if its decomposed 2-tuple linguistic preference relation $Q$ and $T$ are additive consistent, i.e. the following conditions are fulfilled:

$$
\begin{gathered}
q_{i k}=\Delta\left(\Delta^{-1}\left(q_{i j}\right)+\Delta^{-1}\left(q_{j k}\right)-g / 2\right), i, j, k \in N ; \\
t_{i k}=\Delta\left(\Delta^{-1}\left(t_{i j}\right)+\Delta^{-1}\left(t_{j k}\right)-g / 2\right), i, j, k \in N,
\end{gathered}
$$

then all the induced 2-tuple linguistic preference relations $C(\alpha),(\alpha \in[0,1])$ are additive consistent. 

A.

The proof of Theorem 2 is provided in Appendix

Based on the above analysis, we can define the additive consistency of the uncertain 2-tuple linguistic preference relation.

Definition 6. For an uncertain 2-tuple linguistic preference relation $L$, if its decomposed 2-tuple linguistic preference relations $Q$ and $T$ satisfy Eqs. (5) and (6), then $L$ is additive consistent.

By Lemma 1, we can easily obtain an equivalent definition of Definition 6.

Definition 7. For an uncertain 2-tuple linguistic preference relation $L$, if its decomposed 2-tuple linguistic preference relations $Q$ and $T$ satisfy

$$
\begin{gathered}
q_{i k}=\Delta\left(\Delta^{-1}\left(q_{i j}\right)+\Delta^{-1}\left(q_{j k}\right)-g / 2\right), \\
t_{i k}=\Delta\left(\Delta^{-1}\left(t_{i j}\right)+\Delta^{-1}\left(t_{j k}\right)-g / 2\right),
\end{gathered}
$$

for all $i, j, k \in N$ and $i<j<k$, then $L$ is additive consistent.

\section{Algorithms to estimate the missing elements of incomplete uncertain 2-tuple linguistic preference relations}

For actual decision making problems, a difficulty that has to be addressed is the lack of information $15,19,36$. This may be due to an expert not possessing a precise or sufficient level of knowledge for the problem to be solved, or because the expert is unable to discriminate the degree to which some alternatives are better than others. In this case incomplete preference relations may be provided by experts. In this section, we focus on developing some algorithms to estimate the missing elements for an incomplete uncertain 2-tuple linguistic preference relation. To deal with these problems, we will first define the acceptable incomplete uncertain 2-tuple linguistic preference relation.

In this section, we still use the notations as defined in section 3. Let $L=\left(l_{i k}\right)_{n \times n}=\left(\left[l_{i k}^{-}, l_{i k}^{+}\right]\right)_{n \times n}$ be an uncertain 2-tuple linguistic preference relation, $Q=\left(q_{i k}\right)_{n \times n}$ and $T=\left(t_{i k}\right)_{n \times n}$ be its decomposed 2-tuple linguistic preference relations derived by Eq. (4).
Definition 8. An uncertain 2-tuple linguistic preference relation $L$ on a set of alternatives $X$ is called an incomplete uncertain 2-tuple linguistic preference relation if some elements of the preference relation are partially provided or completely not provided.

According to the theorem given by Ref. 32, if an incomplete linguistic preference relation is acceptable, then there exists at least one known element (except diagonal elements) in each line or each column for the preference relation, i.e. at least $n-1$ judgments for the alternatives should be provided. Based on this idea, if we want to estimate the missing elements for an incomplete linguistic preference relation, the preference relation should be acceptable. As a result, we define the acceptable incomplete uncertain 2-tuple linguistic preference relation as follows.

Definition 9. An incomplete uncertain 2-tuple linguistic preference relations $L$ is called acceptable if its decomposed 2-tuple linguistic preference relations $Q$ and $T$ are acceptable, i.e. there exists at least one known element (except diagonal elements) in each line or each column for both $Q$ and $T$.

For an incomplete uncertain 2-tuple linguistic preference relation $L$, we must check whether it is acceptable or not before estimating the missing elements. If it is acceptable, then we can go on estimating the missing elements, otherwise we need to return the preference relation to the decision maker for adjustment until it is acceptable.

If we denote the missing elements of an incomplete uncertain 2-tuple linguistic preference relation $L$ by $\varphi$, then the elements of $L$ can be denoted as

$$
l_{i k}=\left\{\begin{array}{ll}
{\left[l_{i k}^{-}, l_{i k}^{+}\right]} & \text {if } l_{i k} \text { is completely known } \\
{\left[l_{i k}^{-}, \varphi\right]} & \text { if only } l_{i k}^{-} \text {is known } \\
{\left[\varphi, l_{i k}^{+}\right]} & \text {if only } l_{i k}^{+} \text {is known } \\
{[\varphi, \varphi]} & \text { if } l_{i k} \text { is completely unknown }
\end{array} \quad i, k \in N\right.
$$

For the convenience of description, we first give some notations to be used in the following section. Let $\Omega_{Q}$ and $\bar{\Omega}_{Q}$ be the set of known elements and unknown elements of $Q$, respectively. Similarly, let $\Omega_{T}$ and $\bar{\Omega}_{T}$ be the set of known elements and unknown elements of $T$, respectively. In addition, Let $I K_{Q}=\left\{(i, k) \mid q_{i k} \in \bar{\Omega}_{Q}\right\}$ and $I K_{T}=\left\{(i, k) \mid t_{i k} \in \bar{\Omega}_{T}\right\}$ 
denote the label indices of the unknown elements of $Q$ and $T$, respectively, and $J_{Q}^{i k}=\left\{j \mid q_{i j} \in \Omega_{Q}, q_{j k} \in\right.$ $\left.\Omega_{Q}, q_{i k} \in \bar{\Omega}_{Q}\right\}, J_{T}^{i k}=\left\{j \mid t_{i j} \in \Omega_{T}, t_{j k} \in \Omega_{T}, t_{i k} \in\right.$ $\left.\bar{\Omega}_{T}\right\}$.

Based on the additive consistency of the uncertain 2-tuple linguistic preference relation, missing elements $q_{i k} \in \bar{\Omega}_{Q}$ and $t_{i k} \in \bar{\Omega}_{T}$ can be estimated by

$$
\begin{array}{r}
c q_{i k}^{j}=\Delta\left(\Delta^{-1}\left(q_{i j}\right)+\Delta^{-1}\left(q_{j k}\right)-g / 2\right), \\
(i, k) \in I K_{Q}, j \in J_{Q}^{i k} ; \\
c t_{i k}^{j}=\Delta\left(\Delta^{-1}\left(t_{i j}\right)+\Delta^{-1}\left(t_{j k}\right)-g / 2\right), \\
(i, k) \in I K_{T}, j \in J_{T}^{i k},
\end{array}
$$

where $c q_{i k}^{j}$ is the estimated missing value of $q_{i k}$ by $q_{i j}$ and $q_{j k}, c t_{i k}^{j}$ is the estimated missing value of $t_{i k}$ by $t_{i j}$ and $t_{j k}$.

Then the final missing values of $q_{i k} \in \bar{\Omega}_{Q}$ and $t_{i k} \in \bar{\Omega}_{T}$ can be calculated by

$$
\begin{aligned}
c q_{i k} & =\Delta\left(\frac{1}{\# J_{Q}^{i k}} \sum_{j \in J_{Q}^{i k}} \Delta^{-1}\left(c q_{i k}^{j}\right)\right),(i, k) \in I K_{Q} \\
c t_{i k} & =\Delta\left(\frac{1}{\# J_{T}^{i k}} \sum_{j \in J_{T}^{i k}} \Delta^{-1}\left(c t_{i k}^{j}\right)\right),(i, k) \in I K_{T}
\end{aligned}
$$

where $\# J_{Q}^{i k}$ and $\# J_{T}^{i k}$ denote the cardinality of $J_{Q}^{i k}$ and $J_{T}^{i k}$, respectively.

Based on the above analysis, we present an iterative algorithm to estimate the missing elements for an incomplete uncertain 2-tuple linguistic preference relation.

\section{Algorithm I}

Input: an incomplete uncertain 2-tuple linguistic preference relation $L$

Output: a complete uncertain 2-tuple linguistic preference relation $L$

Step 1: Decompose L into two uncertain 2-tuple linguistic preference relations $Q$ and $T$ by $E q$. (4) and check the acceptability of L based on Definition 9. If $L$ is acceptable, go to Step 2; otherwise, return it to the decision maker for adjustment until it is acceptable.
Step 2: Identify and calculate the missing elements of $Q$ and $T$.

Step 2.1 Identify the known elements and missing elements of $Q$ and denote the set$s$ of the known elements and missing elements of $Q$ as $\Omega_{Q}$ and $\bar{\Omega}_{Q}$, respectively. If $\bar{\Omega}_{Q}=\phi$, go to Step 2.4, otherwise go to Step 2.2.

Step 2.2 Let $I K_{Q}=\left\{(i, k) \mid q_{i k} \in \bar{\Omega}_{Q}\right\}, \quad J_{Q}^{i k}=$ $\left\{j \mid q_{i j} \in \Omega_{Q}, q_{j k} \in \Omega_{Q}, q_{i k} \in \bar{\Omega}_{Q}\right\}$. For each $(i, k) \in I K_{Q}$ and $J_{O}^{i k} \neq \phi$, calculate the value of $q_{i k}$ by Eqs. (10) and (12).

Step 2.3 Add all the estimated $q_{i k}$ to $\Omega_{Q}$ and remove all the estimated $q_{i k}$ from $\bar{\Omega}_{Q}$. If $\bar{\Omega}_{Q}=\phi$, go to Step 2.4, otherwise, go to Step 2.2.

Step 2.4 Identify the known elements and missing elements of $T$ and denote the sets of the known elements and missing elements of $T$ as $\Omega_{T}$ and $\bar{\Omega}_{T}$, respectively. If $\bar{\Omega}_{T}=\phi$, go to Step 3, otherwise go to Step 2.5 .

Step 2.5 Let $I K_{T}=\left\{(i, k) \mid t_{i k} \in \bar{\Omega}_{T}\right\}, \quad J_{T}^{i k}=$ $\left\{j \mid t_{i j} \in \Omega_{T}, t_{j k} \in \Omega_{T}, t_{i k} \in \bar{\Omega}_{T}\right\}$. For each $(i, k) \in I K_{T}$ and $J_{T}^{i k} \neq \phi$, calculate the value of $t_{i k}$ by Eqs. (11) and (13).

Step 2.6 Add all the estimated $t_{i k}$ to $\Omega_{T}$ and remove all the estimated $t_{i k}$ from $\bar{\Omega}_{T}$. If $\bar{\Omega}_{T}=\phi$, go to Step 3, otherwise, go to Step 2.5.

Step 3: Construct a complete uncertain 2-tuple linguistic preference relation L by Eq. (4).

For an incomplete uncertain 2-tuple linguistic preference relation, we can estimate the missing elements by Algorithm I. However, by Algorithm I, we may obtain $q_{i k}<t_{i k}$, for $i<k$ or $q_{i k}>t_{i k}$, for $i>k$, i.e., $\Delta^{-1}\left(l_{i k}^{-}\right)>\Delta^{-1}\left(l_{i k}^{+}\right)$, which is unreasonable. In this case, we can adjust the estimated values manually to ensure $\Delta^{-1}\left(l_{i k}^{-}\right) \leqslant \Delta^{-1}\left(l_{i k}^{+}\right)$. However, the adjustment sometimes may be complicated. In 
order to address this problem, we propose another approach in the following section.

As aforementioned, if an uncertain 2-tuple linguistic preference relation is completely consistent, Eqs. (7) and (8) should satisfy. However, in most cases the judgments of decision makers are not completely consistent and Eqs. (7) and (8) will not hold, i.e. there exists some deviation which can be calculated as

$$
\begin{array}{r}
\varepsilon_{i k j}=\left|\Delta^{-1}\left(q_{i k}\right)-\left(\Delta^{-1}\left(q_{i j}\right)+\Delta^{-1}\left(q_{j k}\right)-g / 2\right)\right|, \\
i, j, k \in N \text { and } i<j<k ;
\end{array}
$$

$$
\begin{array}{r}
\eta_{i k j}=\left|\Delta^{-1}\left(t_{i k}\right)-\left(\Delta^{-1}\left(t_{i j}\right)+\Delta^{-1}\left(t_{j k}\right)-g / 2\right)\right|, \\
i, j, k \in N \text { and } i<j<k,
\end{array}
$$

The smaller the deviation $\varepsilon_{i k j}$ and $\eta_{i k j}$ are, the more consistent the judgment will be. Thus we can establish an optimization model to obtain the missing values as

$$
\begin{array}{r}
\min \varepsilon_{i k j}=\left|\Delta^{-1}\left(q_{i k}\right)-\left(\Delta^{-1}\left(q_{i j}\right)+\Delta^{-1}\left(q_{j k}\right)-g / 2\right)\right|, \\
i, j, k \in N, i<j<k ; \\
\eta_{i k j}=\left|\Delta^{-1}\left(t_{i k}\right)-\left(\Delta^{-1}\left(t_{i j}\right)+\Delta^{-1}\left(t_{j k}\right)-g / 2\right)\right|, \\
i, j, k \in N, i<j<k ;
\end{array}
$$

s.t. $\quad \Delta^{-1}\left(q_{i k}\right) \geqslant \Delta^{-1}\left(t_{i k}\right),(i, k) \in I K_{Q} \cup I K_{T}, i<k$;

$$
\Delta^{-1}\left(q_{i k}\right) \in[0, g],(i, k) \in I K_{Q}, i<k
$$$$
\Delta^{-1}\left(t_{i k}\right) \in[0, g],(i, k) \in I K_{T}, i<k .
$$

Note 1: In the model (M-1), $\Delta^{-1}\left(q_{i k}\right),(i, k) \in$ $I K_{Q}, i<k$ and $\Delta^{-1}\left(t_{i k}\right),(i, k) \in I K_{T}, i<k$ are decision variables.

By goal programming, we can transform the model (M-1) into

$$
\begin{array}{ll}
\min & z=\sum_{\substack{i, j, k \in N \\
i<j<k}}\left(\varepsilon_{i k j}^{-}+\varepsilon_{i k j}^{+}\right)+\sum_{\substack{i, j, k \in N \\
i<j<k}}\left(\eta_{i k j}^{-}+\eta_{i k j}^{+}\right) \\
\text {s.t. } & \Delta^{-1}\left(q_{i k}\right)-\left(\Delta^{-1}\left(q_{i j}\right)+\Delta^{-1}\left(q_{j k}\right)-g / 2\right)+\varepsilon_{i k j}^{-}-\varepsilon_{i k j}^{+}=0, i, j, k \in N, i<j<k ; \\
& \Delta^{-1}\left(t_{i k}\right)-\left(\Delta^{-1}\left(t_{i j}\right)+\Delta^{-1}\left(t_{j k}\right)-g / 2\right)+\eta_{i k j}^{-}-\eta_{i k j}^{+}=0, i, j, k \in N, i<j<k ; \\
& \Delta^{-1}\left(q_{i k}\right) \geqslant \Delta^{-1}\left(t_{i k}\right),(i, k) \in I K_{Q} \cup I K_{T}, i<k ; \\
& \Delta^{-1}\left(q_{i k}\right) \in[0, g],(i, k) \in I K_{Q}, i<k ; \\
& \Delta^{-1}\left(t_{i k}\right) \in[0, g],(i, k) \in I K_{T}, i<k ; \\
& \varepsilon_{i k j}^{-}, \varepsilon_{i k j}^{+}, \eta_{i k j}^{-}, \eta_{i k j}^{+} \geqslant 0, i, j, k \in N, i<j<k .
\end{array}
$$

Note 2: In the model $(\mathrm{M}-2), \Delta^{-1}\left(q_{i k}\right),(i, k) \in$ $I K_{Q}$ and $\Delta^{-1}\left(t_{i k}\right)(i, k) \in I K_{T}$ are decision variables, $\varepsilon_{i k j}^{-}, \varepsilon_{i k j}^{+}, \eta_{i k j}^{-}$and $\eta_{i k j}^{+}$are corresponding deviation variables.

By solving the optimization model (M-2), we can obtain the values of $\Delta^{-1}\left(q_{i k}\right)$ and $\Delta^{-1}\left(t_{i k}\right)$. Then we can construct a complete uncertain 2-tuple linguistic preference relation by Eqs. (1) and (4). Note that the solution of the optimization model (M-2) may not be unique. In this case, we can select one complete uncertain 2-tuple linguistic preference relation according to the decision maker's preference.

To summarize, we present Algorithm II.

\begin{abstract}
Algorithm II
Input: an incomplete uncertain 2-tuple linguistic preference relation $L$

Output: a complete uncertain 2-tuple linguistic preference relation $L$
\end{abstract}

Step 1: See Step 1 of Algorithm I.

Step 2: Identify the sets of missing elements and known elements for $Q$ and $T$.

Step 3: Calculate the values of the missing elements by the model (M-2).

Step 4: Construct a complete uncertain 2-tuple linguistic preference relation L by Eqs. (1) and 
(4).

\section{Illustrative examples}

In this section, we present some numerical examples to illustrate the two algorithms.

Example 1. Let the linguistic term set be $S=\left\{s_{0}\right.$ : very poor, $s_{1}$ : poor, $s_{2}:$ slightly poor, $s_{3}:$ fair, $s_{4}$ : slightly good, $s_{5}$ : good, $s_{6}$ : very good $\}$ and consider the following incomplete uncertain linguistic preference relation:

$$
L=\left(\begin{array}{cccc}
{\left[s_{3}, s_{3}\right]} & {[\varphi, \varphi]} & {\left[s_{2}, \varphi\right]} & {[\varphi, \varphi]} \\
{[\varphi, \varphi]} & {\left[s_{3}, s_{3}\right]} & {[\varphi, \varphi]} & {\left[s_{1}, s_{2}\right]} \\
{\left[\varphi, s_{4}\right]} & {[\varphi, \varphi]} & {\left[s_{3}, s_{3}\right]} & {\left[s_{3}, s_{3}\right]} \\
{[\varphi, \varphi]} & {\left[s_{4}, s_{5}\right]} & {\left[s_{3}, s_{3}\right]} & {\left[s_{3}, s_{3}\right]}
\end{array}\right)
$$

In what follows, we use Algorithm I to estimate the missing elements.

Step 1: Check the acceptability of $L$. First, we transform $L$ into an uncertain 2-tuple linguistic preference relation and decompose it as

$$
\begin{gathered}
Q=\left(\begin{array}{cccc}
\left(s_{3}, 0\right) & \varphi & \varphi & \varphi \\
\varphi & \left(s_{3}, 0\right) & \varphi & \left(s_{2}, 0\right) \\
\varphi & \varphi & \left(s_{3}, 0\right) & \left(s_{3}, 0\right) \\
\varphi & \left(s_{4}, 0\right) & \left(s_{3}, 0\right) & \left(s_{3}, 0\right)
\end{array}\right), \\
T=\left(\begin{array}{cccc}
\left(s_{3}, 0\right) & \varphi & \left(s_{2}, 0\right) & \varphi \\
\varphi & \left(s_{3}, 0\right) & \varphi & \left(s_{1}, 0\right) \\
\left(s_{4}, 0\right) & \varphi & \left(s_{3}, 0\right) & \left(s_{3}, 0\right) \\
\varphi & \left(s_{5}, 0\right) & \left(s_{3}, 0\right) & \left(s_{3}, 0\right)
\end{array}\right) .
\end{gathered}
$$

We can find that $Q$ is unacceptable, so we return $L$ to the expert for adjustment and a new preference relation is obtained as

$$
L=\left(\begin{array}{llll}
{\left[s_{3}, s_{3}\right]} & {\left[\varphi, s_{4}\right]} & {\left[s_{2}, \varphi\right]} & {[\varphi, \varphi]} \\
{\left[s_{2}, \varphi\right]} & {\left[s_{3}, s_{3}\right]} & {[\varphi, \varphi]} & {\left[s_{1}, s_{2}\right]} \\
{\left[\varphi, s_{4}\right]} & {[\varphi, \varphi]} & {\left[s_{3}, s_{3}\right]} & {\left[s_{3}, s_{3}\right]} \\
{[\varphi, \varphi]} & {\left[s_{4}, s_{5}\right]} & {\left[s_{3}, s_{3}\right]} & {\left[s_{3}, s_{3}\right]}
\end{array}\right)
$$

Then we have

$$
\begin{aligned}
Q & =\left(\begin{array}{cccc}
\left(s_{3}, 0\right) & \left(s_{4}, 0\right) & \varphi & \varphi \\
\left(s_{2}, 0\right) & \left(s_{3}, 0\right) & \varphi & \left(s_{2}, 0\right) \\
\varphi & \varphi & \left(s_{3}, 0\right) & \left(s_{3}, 0\right) \\
\varphi & \left(s_{4}, 0\right) & \left(s_{3}, 0\right) & \left(s_{3}, 0\right)
\end{array}\right), \\
T & =\left(\begin{array}{cccc}
\left(s_{3}, 0\right) & \varphi & \left(s_{2}, 0\right) & \varphi \\
\varphi & \left(s_{3}, 0\right) & \varphi & \left(s_{1}, 0\right) \\
\left(s_{4}, 0\right) & \varphi & \left(s_{3}, 0\right) & \left(s_{3}, 0\right) \\
\varphi & \left(s_{5}, 0\right) & \left(s_{3}, 0\right) & \left(s_{3}, 0\right)
\end{array}\right) .
\end{aligned}
$$

By Definition $9, L$ is acceptable.

Step 2: (a) Identify the sets of known elements and missing elements of $Q$. By Step 2.2 of Algorithm I, we have $I K_{Q}=$ $\{(1,3)(1,4)(2,3)(3,1)(3,2)(4,1)\}, \quad J_{Q}^{14}=J_{Q}^{41}=$ $\{2\}, J_{Q}^{23}=J_{Q}^{32}=\{4\}, J_{Q}^{13}=J_{Q}^{31}=\phi$. By Eqs. (10) and (12), we have

$$
\begin{gathered}
\left.c q_{14}=c q_{14}^{2}=\Delta\left(\Delta^{-1}\left(q_{12}\right)+\Delta^{-1}\left(q_{24}\right)-g / 2\right)\right)=\left(s_{3}, 0\right), \\
c q_{41}=\operatorname{Neg}\left(c q_{14}\right)=\left(s_{3}, 0\right) ; \\
\left.c q_{23}=c q_{23}^{4}=\Delta\left(\Delta^{-1}\left(q_{24}\right)+\Delta^{-1}\left(q_{43}\right)-g / 2\right)\right)=\left(s_{2}, 0\right), \\
c q_{32}=\operatorname{Neg}\left(c q_{23}\right)=\left(s_{4}, 0\right) .
\end{gathered}
$$

After that, we update $I K_{Q}$ as $I K_{Q}=\{(1,3)(3,1)\}$ and $J_{Q}^{13}=\{2,4\}$. Thus we can obtain

$$
\begin{gathered}
\left.c q_{13}^{2}=\Delta\left(\Delta^{-1}\left(q_{12}\right)+\Delta^{-1}\left(q_{23}\right)-g / 2\right)\right)=\left(s_{3}, 0\right), \\
\left.c q_{13}^{4}=\Delta\left(\Delta^{-1}\left(q_{14}\right)+\Delta^{-1}\left(q_{43}\right)-g / 2\right)\right)=\left(s_{3}, 0\right), \\
c q_{13}=\Delta\left(\frac{1}{2}\left(\Delta^{-1}\left(c q_{13}^{2}\right)+\Delta^{-1}\left(c q_{13}^{4}\right)\right)\right)=\left(s_{3}, 0\right), \\
c q_{31}=\operatorname{Neg}\left(c q_{13}\right)=\left(s_{3}, 0\right) .
\end{gathered}
$$

(b) Identify the sets of known elements and missing elements of $T$. By Step 2.5 of Algorithm I, we have $I K_{T}=\{(1,2)(1,4)(2,1)(2,3)(3,2)(4,1)\}$, $J_{T}^{14}=J_{T}^{41}=\{3\}, J_{T}^{23}=J_{T}^{32}=\{4\}, J_{T}^{12}=J_{T}^{21}=\phi$. By Eqs. (11) and (13), we have

$$
\begin{aligned}
c t_{14}=c t_{14}^{3}= & \left.\Delta\left(\Delta^{-1}\left(t_{13}\right)+\Delta^{-1}\left(t_{34}\right)-g / 2\right)\right)=\left(s_{2}, 0\right), \\
& c t_{41}=\operatorname{Neg}\left(c t_{14}\right)=\left(s_{4}, 0\right) ; \\
c t_{23}=c t_{23}^{4}= & \left.\Delta\left(\Delta^{-1}\left(t_{24}\right)+\Delta^{-1}\left(t_{43}\right)-g / 2\right)\right)=\left(s_{1}, 0\right), \\
& c t_{32}=\operatorname{Neg}\left(c t_{23}\right)=\left(s_{5}, 0\right) ;
\end{aligned}
$$

Then we update $I K_{T}$ as $I K_{T}=\{(1,2)(2,1)\}$ and $J_{Q}^{12}=J_{Q}^{21}=\{3,4\}$. Thus we can obtain

$$
\begin{gathered}
\left.c t_{12}^{3}=\Delta\left(\Delta^{-1}\left(t_{13}\right)+\Delta^{-1}\left(t_{32}\right)-g / 2\right)\right)=\left(s_{4}, 0\right), \\
\left.c t_{12}^{4}=\Delta\left(\Delta^{-1}\left(t_{14}\right)+\Delta^{-1}\left(t_{42}\right)-g / 2\right)\right)=\left(s_{4}, 0\right), \\
c t_{12}=\Delta\left(\frac{1}{2}\left(\Delta^{-1}\left(c t_{12}^{3}\right)+\Delta^{-1}\left(c t_{12}^{4}\right)\right)\right)=\left(s_{4}, 0\right), \\
c t_{21}=\operatorname{Neg}\left(c t_{12}\right)=\left(s_{2}, 0\right) .
\end{gathered}
$$

In this case, all the missing elements are estimated. Thus we can obtain a complete uncertain 2-tuple linguistic preference relation as 


$$
L=\left(\begin{array}{llll}
{\left[\left(s_{3}, 0\right),\left(s_{3}, 0\right)\right]} & {\left[\left(s_{4}, 0\right),\left(s_{4}, 0\right)\right]} & {\left[\left(s_{2}, 0\right),\left(s_{3}, 0\right)\right]} & {\left[\left(s_{2}, 0\right),\left(s_{3}, 0\right)\right]} \\
{\left[\left(s_{2}, 0\right),\left(s_{2}, 0\right)\right]} & {\left[\left(s_{3}, 0\right),\left(s_{3}, 0\right)\right]} & {\left[\left(s_{1}, 0\right),\left(s_{2}, 0\right)\right]} & {\left[\left(s_{1}, 0\right),\left(s_{2}, 0\right)\right]} \\
{\left[\left(s_{3}, 0\right),\left(s_{4}, 0\right)\right]} & {\left[\left(s_{4}, 0\right),\left(s_{5}, 0\right)\right]} & {\left[\left(s_{3}, 0\right),\left(s_{3}, 0\right)\right]} & {\left[\left(s_{3}, 0\right),\left(s_{3}, 0\right)\right]} \\
{\left[\left(s_{3}, 0\right),\left(s_{4}, 0\right)\right]} & {\left[\left(s_{4}, 0\right),\left(s_{5}, 0\right)\right]} & {\left[\left(s_{3}, 0\right),\left(s_{3}, 0\right)\right]} & {\left[\left(s_{3}, 0\right),\left(s_{3}, 0\right)\right]}
\end{array}\right)
$$

If we adopt Algorithm II, we can establish the

following optimization model:

$$
\begin{array}{ll}
\min \quad z= & \varepsilon_{132}^{-}+\varepsilon_{132}^{+}+\varepsilon_{142}^{-}+\varepsilon_{142}^{+}+\varepsilon_{143}^{-}+\varepsilon_{143}^{+}+\varepsilon_{243}^{-}+\varepsilon_{243}^{+}+\eta_{132}^{-}+\eta_{132}^{+} \\
& +\eta_{142}^{-}+\eta_{142}^{+}+\eta_{143}^{-}+\eta_{143}^{+}+\eta_{243}^{-}+\eta_{243}^{+} \\
\text {s.t. } \quad & \Delta^{-1}\left(q_{13}\right)-\left(4+\Delta^{-1}\left(q_{23}\right)-3\right)+\varepsilon_{132}^{-}-\varepsilon_{132}^{+}=0 ; \Delta^{-1}\left(q_{14}\right)-(4+2-3)+\varepsilon_{142}^{-}-\varepsilon_{142}^{+}=0 ; \\
& \Delta^{-1}\left(q_{14}\right)-\left(\Delta^{-1}\left(q_{13}\right)+3-3\right)+\varepsilon_{143}^{-}-\varepsilon_{143}^{+}=0 ; 2-\left(\Delta^{-1}\left(q_{23}\right)+3-3\right)+\varepsilon_{243}^{-}-\varepsilon_{243}^{+}=0 ; \\
& 2-\left(\Delta^{-1}\left(t_{12}\right)+\Delta^{-1}\left(t_{23}\right)-3\right)+\eta_{132}^{-}-\eta_{132}^{+}=0 ; \Delta^{-1}\left(t_{14}\right)-\left(\Delta^{-1}\left(t_{12}\right)+1-3\right)+\eta_{142}^{-}-\eta_{142}^{+}=0 ; \\
& \Delta^{-1}\left(t_{14}\right)-(2+3-3)+\eta_{143}^{-}-\eta_{143}^{+}=0 ; 1-\left(\Delta^{-1}\left(t_{23}\right)+3-3\right)+\eta_{243}^{-}-\eta_{243}^{+}=0 ; \\
& \Delta^{-1}\left(q_{14}\right) \geqslant \Delta^{-1}\left(t_{14}\right), \Delta^{-1}\left(q_{23}\right) \geqslant \Delta^{-1}\left(t_{23}\right) ; \\
& \Delta^{-1}\left(q_{13}\right) \in[2,6], \Delta^{-1}\left(t_{12}\right) \in[0,4] ; \\
& \Delta^{-1}\left(q_{14}\right), \Delta^{-1}\left(q_{23}\right), \Delta^{-1}\left(t_{14}\right), \Delta^{-1}\left(t_{23}\right) \in[0,6] ; \\
& \varepsilon_{132}^{-}, \varepsilon_{132}^{+}, \varepsilon_{143}^{-}, \varepsilon_{143}^{+}, \varepsilon_{243}^{-}, \varepsilon_{243}^{+}, \eta_{132}^{-}, \eta_{132}^{+}, \eta_{143}^{-}, \eta_{143}^{+}, \eta_{243}^{-}, \eta_{243}^{+} \geqslant 0 .
\end{array}
$$

By solving the model (M-3), we can obtain $\Delta^{-1}\left(q_{13}\right)=3, \Delta^{-1}\left(q_{23}\right)=2, \Delta^{-1}\left(q_{14}\right)=3$, $\Delta^{-1}\left(t_{12}\right)=4, \Delta^{-1}\left(t_{23}\right)=1, \Delta^{-1}\left(t_{14}\right)=2$. Thus we

$$
L=\left(\begin{array}{llll}
{\left[\left(s_{3}, 0\right),\left(s_{3}, 0\right)\right]} & {\left[\left(s_{4}, 0\right),\left(s_{4}, 0\right)\right]} & {\left[\left(s_{2}, 0\right),\left(s_{3}, 0\right)\right]} & {\left[\left(s_{2}, 0\right),\left(s_{3}, 0\right)\right]} \\
{\left[\left(s_{2}, 0\right),\left(s_{2}, 0\right)\right]} & {\left[\left(s_{3}, 0\right),\left(s_{3}, 0\right)\right]} & {\left[\left(s_{1}, 0\right),\left(s_{2}, 0\right)\right]} & {\left[\left(s_{1}, 0\right),\left(s_{2}, 0\right)\right]} \\
{\left[\left(s_{3}, 0\right),\left(s_{4}, 0\right)\right]} & {\left[\left(s_{4}, 0\right),\left(s_{5}, 0\right)\right]} & {\left[\left(s_{3}, 0\right),\left(s_{3}, 0\right)\right]} & {\left[\left(s_{3}, 0\right),\left(s_{3}, 0\right)\right]} \\
{\left[\left(s_{3}, 0\right),\left(s_{4}, 0\right)\right]} & {\left[\left(s_{4}, 0\right),\left(s_{5}, 0\right)\right]} & {\left[\left(s_{3}, 0\right),\left(s_{3}, 0\right)\right]} & {\left[\left(s_{3}, 0\right),\left(s_{3}, 0\right)\right]}
\end{array}\right),
$$

which is the same as the result obtained by Algorith$\mathrm{m} \mathrm{I}$.

Example 2. Let the linguistic term set be $S=$ $\left\{s_{0}\right.$ : extremely poor, $s_{1}$ : very poor, $s_{2}$ : poor, $s_{3}$ : slightly poor, $s_{4}$ : fair, $s_{5}:$ slightly good, $s_{6}: \operatorname{good}, s_{7}$ : very good, $s_{8}$ : extremely good $\}$ and consider another uncertain linguistic preference relation

$L_{1}=\left(\begin{array}{ccccc}{\left[s_{4}, s_{4}\right]} & {\left[s_{2}, s_{5}\right]} & {\left[s_{5}, s_{5}\right]} & {\left[\varphi, s_{3}\right]} & {\left[\varphi, s_{4}\right]} \\ {\left[s_{3}, s_{6}\right]} & {\left[s_{4}, s_{4}\right]} & {\left[s_{5}, s_{7}\right]} & {[\varphi, \varphi]} & {\left[\varphi, s_{4}\right]} \\ {\left[s_{3}, s_{3}\right]} & {\left[s_{1}, s_{3}\right]} & {\left[s_{4}, s_{4}\right]} & {\left[s_{3}, s_{4}\right]} & {[\varphi, \varphi]} \\ {\left[s_{5}, \varphi\right]} & {[\varphi, \varphi]} & {\left[s_{4}, s_{5}\right]} & {\left[s_{4}, s_{4}\right]} & {\left[s_{3}, s_{4}\right]} \\ {\left[s_{4}, \varphi\right]} & {\left[s_{4}, \varphi\right]} & {[\varphi, \varphi]} & {\left[s_{4}, s_{5}\right]} & {\left[s_{4}, s_{4}\right]}\end{array}\right)$

If we adopt Algorithm I, we can obtain the decomposed 2-tuple linguistic preference relations of

$L_{1}$ as $\left.\Delta\left(\Delta^{-1}\left(t_{13}\right)+\Delta^{-1}\left(t_{34}\right)-g / 2\right)\right)=\left(s_{4}, 0\right)$. can construct the complete uncertain 2-tuple linguistic preference relation as

$$
Q=\left(\begin{array}{ccccc}
\left(s_{4}, 0\right) & \left(s_{5}, 0\right) & \left(s_{5}, 0\right) & \left(s_{3}, 0\right) & \left(s_{4}, 0\right) \\
\left(s_{3}, 0\right) & \left(s_{4}, 0\right) & \left(s_{7}, 0\right) & \varphi & \left(s_{4}, 0\right) \\
\left(s_{3}, 0\right) & \left(s_{1}, 0\right) & \left(s_{4}, 0\right) & \left(s_{4}, 0\right) & \varphi \\
\left(s_{5}, 0\right) & \varphi & \left(s_{4}, 0\right) & \left(s_{4}, 0\right) & \left(s_{4}, 0\right) \\
\left(s_{4}, 0\right) & \left(s_{4}, 0\right) & \varphi & \left(s_{4}, 0\right) & \left(s_{4}, 0\right)
\end{array}\right)
$$

$T=\left(\begin{array}{ccccc}\left(s_{4}, 0\right) & \left(s_{2}, 0\right) & \left(s_{5}, 0\right) & \varphi & \varphi \\ \left(s_{6}, 0\right) & \left(s_{4}, 0\right) & \left(s_{5}, 0\right) & \varphi & \varphi \\ \left(s_{3}, 0\right) & \left(s_{3}, 0\right) & \left(s_{4}, 0\right) & \left(s_{3}, 0\right) & \varphi \\ \varphi & \varphi & \left(s_{5}, 0\right) & \left(s_{4}, 0\right) & \left(s_{3}, 0\right) \\ \varphi & \varphi & \varphi & \left(s_{5}, 0\right) & \left(s_{4}, 0\right)\end{array}\right)$

Then we can find both $Q$ and $T$ are acceptable. For $T$, if we estimate $t_{14}$, we can obtain $c t_{14}=c t_{14}^{3}=$ 
In this case, we have $t_{14}>q_{14}$, which contradicts with Eq. (4). To deal with this problem we need the decision maker to adjust the value of $t_{14}$ manually. If the decision maker doesn't want to participate in the process, Algorithm I will not work. So Algorith- $\mathrm{m} \mathrm{I}$ is not very robust sometimes. In what follows we utilize Algorithm II to estimate the missing elements for $L_{1}$. For $L_{1}$, we can establish the following optimization model:

$$
\begin{array}{ll}
\min \quad z= & \varepsilon_{142}^{-}+\varepsilon_{142}^{+}+\varepsilon_{153}^{-}+\varepsilon_{153}^{+}+\varepsilon_{243}^{-}+\varepsilon_{243}^{+}+\varepsilon_{253}^{-}+\varepsilon_{253}^{+}+\varepsilon_{254}^{-}+\varepsilon_{254}^{+}+\varepsilon_{354}^{-}+\varepsilon_{354}^{+}+\eta_{142}^{-} \\
& +\eta_{142}^{+}+\eta_{152}^{-}+\eta_{152}^{+}+\eta_{143}^{-}+\eta_{143}^{+}+\eta_{153}^{-}+\eta_{153}^{+}+\eta_{154}^{-}+\eta_{154}^{+}+\eta_{243}^{-}+\eta_{243}^{+}+\eta_{253}^{-} \\
& +\eta_{253}^{+}+\eta_{254}^{-}+\eta_{254}^{+}+\eta_{354}^{-}+\eta_{354}^{+} \\
\text {s.t. } \quad 3 & -\left(5+\Delta^{-1}\left(q_{24}\right)-4\right)+\varepsilon_{142}^{-}-\varepsilon_{142}^{+}=0,4-\left(5+\Delta^{-1}\left(q_{35}\right)-4\right)+\varepsilon_{153}^{-}-\varepsilon_{153}^{+}=0 ; \\
& \Delta^{-1}\left(q_{24}\right)-(7+4-4)+\varepsilon_{243}^{-}-\varepsilon_{243}^{+}=0,4-\left(7+\Delta^{-1}\left(q_{35}\right)-4\right)+\varepsilon_{253}^{-}-\varepsilon_{253}^{+}=0 ; \\
& 4-\left(\Delta^{-1}\left(q_{24}\right)+4-4\right)+\varepsilon_{254}^{-}-\varepsilon_{254}^{+}=0, \Delta^{-1}\left(q_{35}\right)-(4+4-4)+\varepsilon_{354}^{-}-\varepsilon_{354}^{+}=0 ; \\
& \Delta^{-1}\left(t_{14}\right)-\left(2+\Delta^{-1}\left(t_{24}\right)-4\right)+\eta_{142}^{-}-\eta_{142}^{+}=0, \Delta^{-1}\left(t_{15}\right)-\left(2+\Delta^{-1}\left(t_{25}\right)-4\right)+\eta_{152}^{-}-\eta_{152}^{+}=0 ; \\
& \Delta^{-1}\left(t_{14}\right)-(5+3-4)+\eta_{143}^{-}-\eta_{143}^{+}=0, \Delta^{-1}\left(t_{15}\right)-\left(5+\Delta^{-1}\left(t_{35}\right)-4\right)+\eta_{153}^{-}-\eta_{153}^{+}=0 ; \\
& \Delta^{-1}\left(t_{15}\right)-\left(\Delta^{-1}\left(t_{14}\right)+3-4\right)+\eta_{154}^{-}-\eta_{154}^{+}=0, \Delta^{-1}\left(t_{24}\right)-(5+3-4)+\eta_{243}^{-}-\eta_{243}^{+}=0 ; \\
& \Delta^{-1}\left(t_{25}\right)-\left(5+\Delta^{-1}\left(t_{35}\right)-4\right)+\eta_{253}^{-}-\eta_{253}^{+}=0, \Delta^{-1}\left(t_{25}\right)-\left(\Delta^{-1}\left(t_{24}\right)+3-4\right)+\eta_{254}^{-}-\eta_{254}^{+}=0 ; \\
& \Delta^{-1}\left(t_{35}\right)-(3+3-4)+\eta_{354}^{-}-\eta_{354}^{+}=0 ; \\
& \Delta^{-1}\left(q_{24}\right) \geqslant \Delta^{-1}\left(t_{24}\right) ; \Delta^{-1}\left(q_{35}\right) \geqslant \Delta^{-1}\left(t_{35}\right) ; \\
& \Delta^{-1}\left(q_{24}\right) \in[0,8], \Delta^{-1}\left(q_{35}\right) \in[0,8], \Delta^{-1}\left(t_{14}\right) \in[0,3], \Delta^{-1}\left(t_{15}\right) \in[0,4] ; \\
& \Delta^{-1}\left(t_{24}\right) \in[0,8] ; \Delta^{-1}\left(t_{25}\right) \in[0,4], \Delta^{-1}\left(t_{35}\right) \in[0,8] ; \\
& \varepsilon_{142}^{-}, \varepsilon_{142}^{+}, \varepsilon_{153}^{-}, \varepsilon_{153}^{+} \varepsilon_{243}^{-}, \varepsilon_{243}^{+}, \varepsilon_{253}^{-}, \varepsilon_{253}^{+}, \varepsilon_{254}^{-}, \varepsilon_{254}^{+}, \varepsilon_{354}^{-}, \varepsilon_{354}^{+}, \eta_{142}^{-}, \eta_{142}^{+}, \eta_{152}^{-}, \eta_{152}^{+}, \eta_{143}^{-}, \eta_{143}^{+}, \\
& \eta_{153}^{-}, \eta_{153}^{+}, \eta_{154}^{-}, \eta_{154}^{+}, \eta_{243}^{-}, \eta_{243}^{+}, \eta_{253}^{-}, \eta_{253}^{+}, \eta_{254}^{-}, \eta_{254}^{+}, \eta_{354}^{-}, \eta_{354}^{+} \geqslant 0 .
\end{array}
$$

By solving the optimization model (M-4), we can easily obtain $\Delta^{-1}\left(q_{24}\right)=4, \Delta^{-1}\left(q_{35}\right)=3$, $\Delta^{-1}\left(t_{14}\right)=2, \Delta^{-1}\left(t_{15}\right)=1, \Delta^{-1}\left(t_{24}\right)=4, \Delta^{-1}\left(t_{25}\right)=$ $3, \Delta^{-1}\left(t_{35}\right)=2$, or $\Delta^{-1}\left(q_{24}\right)=4, \Delta^{-1}\left(q_{35}\right)=3$,

$$
\begin{aligned}
& \Delta^{-1}\left(t_{14}\right)=3, \Delta^{-1}\left(t_{15}\right)=2, \Delta^{-1}\left(t_{24}\right)=4, \Delta^{-1}\left(t_{25}\right)= \\
& 3, \Delta^{-1}\left(t_{35}\right)=2 .
\end{aligned}
$$

Thus we can obtain a complete uncertain 2-tuple linguistic preference relation as

or

$$
L_{1}=\left(\begin{array}{l}
{\left[\left(s_{4}, 0\right),\left(s_{4}, 0\right)\right]\left[\left(s_{2}, 0\right),\left(s_{5}, 0\right)\right]\left[\left(s_{5}, 0\right),\left(s_{5}, 0\right)\right]\left[\left(s_{2}, 0\right),\left(s_{3}, 0\right)\right]\left[\left(s_{1}, 0\right),\left(s_{4}, 0\right)\right]} \\
{\left[\left(s_{3}, 0\right),\left(s_{6}, 0\right)\right]\left[\left(s_{4}, 0\right),\left(s_{4}, 0\right)\right]\left[\left(s_{5}, 0\right),\left(s_{7}, 0\right)\right]\left[\left(s_{4}, 0\right),\left(s_{4}, 0\right)\right]\left[\left(s_{3}, 0\right),\left(s_{4}, 0\right)\right]} \\
{\left[\left(s_{3}, 0\right),\left(s_{3}, 0\right)\right]\left[\left(s_{1}, 0\right),\left(s_{3}, 0\right)\right]\left[\left(s_{4}, 0\right),\left(s_{4}, 0\right)\right]\left[\left(s_{3}, 0\right),\left(s_{4}, 0\right)\right]\left[\left(s_{2}, 0\right),\left(s_{3}, 0\right)\right]} \\
{\left[\left(s_{5}, 0\right),\left(s_{6}, 0\right)\right]\left[\left(s_{4}, 0\right),\left(s_{4}, 0\right)\right]\left[\left(s_{4}, 0\right),\left(s_{5}, 0\right)\right]\left[\left(s_{4}, 0\right),\left(s_{4}, 0\right)\right]\left[\left(s_{3}, 0\right),\left(s_{4}, 0\right)\right]} \\
{\left[\left(s_{4}, 0\right),\left(s_{7}, 0\right)\right]\left[\left(s_{4}, 0\right),\left(s_{5}, 0\right)\right]\left[\left(s_{5}, 0\right),\left(s_{6}, 0\right)\right]\left[\left(s_{4}, 0\right),\left(s_{5}, 0\right)\right]\left[\left(s_{4}, 0\right),\left(s_{4}, 0\right)\right]}
\end{array}\right)
$$

$$
L_{1}=\left(\begin{array}{l}
{\left[\left(s_{4}, 0\right),\left(s_{4}, 0\right)\right]\left[\left(s_{2}, 0\right),\left(s_{5}, 0\right)\right]\left[\left(s_{5}, 0\right),\left(s_{5}, 0\right)\right]\left[\left(s_{3}, 0\right),\left(s_{3}, 0\right)\right]\left[\left(s_{2}, 0\right),\left(s_{4}, 0\right)\right]} \\
{\left[\left(s_{3}, 0\right),\left(s_{6}, 0\right)\right]\left[\left(s_{4}, 0\right),\left(s_{4}, 0\right)\right]\left[\left(s_{5}, 0\right),\left(s_{7}, 0\right)\right]\left[\left(s_{4}, 0\right),\left(s_{4}, 0\right)\right]\left[\left(s_{3}, 0\right),\left(s_{4}, 0\right)\right]} \\
{\left[\left(s_{3}, 0\right),\left(s_{3}, 0\right)\right]\left[\left(s_{1}, 0\right),\left(s_{3}, 0\right)\right]\left[\left(s_{4}, 0\right),\left(s_{4}, 0\right)\right]\left[\left(s_{3}, 0\right),\left(s_{4}, 0\right)\right]\left[\left(s_{2}, 0\right),\left(s_{3}, 0\right)\right]} \\
{\left[\left(s_{5}, 0\right),\left(s_{5}, 0\right)\right]\left[\left(s_{4}, 0\right),\left(s_{4}, 0\right)\right]\left[\left(s_{4}, 0\right),\left(s_{5}, 0\right)\right]\left[\left(s_{4}, 0\right),\left(s_{4}, 0\right)\right]\left[\left(s_{3}, 0\right),\left(s_{4}, 0\right)\right]} \\
{\left[\left(s_{4}, 0\right),\left(s_{6}, 0\right)\right]\left[\left(s_{4}, 0\right),\left(s_{5}, 0\right)\right]\left[\left(s_{5}, 0\right),\left(s_{6}, 0\right)\right]\left[\left(s_{4}, 0\right),\left(s_{5}, 0\right)\right]\left[\left(s_{4}, 0\right),\left(s_{4}, 0\right)\right]}
\end{array}\right)
$$


As aforementioned, we may obtain $t_{14}=\left(s_{4}, 0\right)$ when Algorithm I is implemented, which is unreasonable. In this case, we can adjust the value of $t_{14}$ as $\left(s_{2}, 0\right)$ or $\left(s_{3}, 0\right)$ manually and there will be also multiple estimation results for the complete preference relation. Thus the two preference relations obtained by Algorithm II are reasonable.

\section{Discussions and Conclusions}

In this paper, we first define the additive consistency of the uncertain 2-tuple linguistic preference relation. Based on the additive consistency, we propose two algorithms to estimate the missing elements for an incomplete uncertain 2-tuple linguistic preference relation. By comparing the two algorithms with two numerical examples, we can find they have the following characteristics.

Algorithm I is an iterative algorithm which may result in unreasonable results, thus it sometimes needs the interactions of decision makers. However, Algorithm II is an optimization-based algorithm which doesn't need the interactions of decision makers. Thus it is an automatic algorithm. In the case when it is urgent to obtain a solution of the preference relation, or decision makers cannot or are unwilling to participate in the estimation process, Algorithm 2 will work well. Besides, the objective function of the model (M-2) is in fact to maximize the consistency of the preference relation, therefore the obtained preference relations sometimes will be with higher consistency than the iterative algorithm sometimes. To summarize, we can find that Algorithm II is more robust.

In terms of future work, we will focus on investigating new approaches to group decision making with incomplete uncertain 2-tuple linguistic preference relations. Besides, we also intend to develop a decision support system to help decision makers estimate the missing elements.

\section{Acknowledgements}

The authors thank the editor and the four anonymous referees for their insightful and constructive comments and suggestions that have led to an im- proved version of this paper. This work was partly supported by the National Natural Science Foundation of China (No. 71171030), the Key Program of National Natural Science Foundation of China (No. 71031002) and the Program for New Century Excellent Talents in University (NECT-11-0050).

\section{Appendix A Proofs of the theorems}

\section{Proof of Lemma 1}

Proof. (i) $\Rightarrow$ (ii) is obvious. In what follows, we will prove (ii) $\Rightarrow$ (i). If two or three of the indices $i, j, k$ are equal, (i) will reduces to the reciprocity condition of 2-tuple linguistic preference relation. Therefore, we only need to consider the cases in which the indices $i, j, k$ take different values. The following six cases are considered:

Case 1: $i<j<k$. In this case, (i) reduces to (ii), and therefore (i) is true.

Case 2: $i<k<j$. In this case, we have $p_{i j}=$ $\Delta\left(\Delta^{-1}\left(p_{i k}\right)+\Delta^{-1}\left(p_{k j}\right)-g / 2\right)$, which is equivalent to $\Delta^{-1}\left(p_{i j}\right)=\Delta^{-1}\left(p_{i k}\right)+\Delta^{-1}\left(p_{k j}\right)-g / 2$. Using the reciprocity property, we have $\Delta^{-1}\left(p_{i j}\right)=\Delta^{-1}\left(p_{i k}\right)+$ $g-\Delta^{-1}\left(p_{j k}\right)-g / 2$, i.e., $\Delta^{-1}\left(p_{i k}\right)=\Delta^{-1}\left(p_{i j}\right)+$ $\Delta^{-1}\left(p_{j k}\right)-g / 2$.

Case 3: $j<i<k$. We have $p_{j k}=$ $\Delta\left(\Delta^{-1}\left(p_{j i}\right)+\Delta^{-1}\left(p_{i k}\right)-g / 2\right)$, which is equivalen$\mathrm{t}$ to $\Delta^{-1}\left(p_{j k}\right)=\Delta^{-1}\left(p_{j i}\right)+\Delta^{-1}\left(p_{i k}\right)-g / 2$. Using the reciprocity property, we have $\Delta^{-1}\left(p_{j k}\right)=$ $g-\Delta^{-1}\left(p_{i j}\right)+\Delta^{-1}\left(p_{i k}\right)-g / 2$, i.e., $\Delta^{-1}\left(p_{i k}\right)=$ $\Delta^{-1}\left(p_{i j}\right)+\Delta^{-1}\left(p_{j k}\right)-g / 2$.

Case 4: $j<k<i$. We have $p_{j i}=$ $\Delta\left(\Delta^{-1}\left(p_{j k}\right)+\Delta^{-1}\left(p_{k i}\right)-g / 2\right)$, which is equivalen$\mathrm{t}$ to $\Delta^{-1}\left(p_{j i}\right)=\Delta^{-1}\left(p_{j k}\right)+\Delta^{-1}\left(p_{k i}\right)-g / 2$. Using the reciprocity property, we have $g-\Delta^{-1}\left(p_{i j}\right)=$ $\Delta^{-1}\left(p_{j k}\right)+g-\Delta^{-1}\left(p_{i k}\right)-g / 2$, i.e., $\Delta^{-1}\left(p_{i k}\right)=$ $\Delta^{-1}\left(p_{i j}\right)+\Delta^{-1}\left(p_{j k}\right)-g / 2$.

Case 5: $k<i<j$. We have $p_{k j}=$ $\Delta\left(\Delta^{-1}\left(p_{k i}\right)+\Delta^{-1}\left(p_{i j}\right)-g / 2\right)$, which is equivalent to $\Delta^{-1}\left(p_{k j}\right)=\Delta^{-1}\left(p_{k i}\right)+\Delta^{-1}\left(p_{i j}\right)-g / 2$. Using the reciprocity property, we have $g-\Delta^{-1}\left(p_{k j}\right)=$ $g-\Delta^{-1}\left(p_{i k}\right)+\Delta^{-1}\left(p_{i j}\right)-g / 2$, i.e., $\Delta^{-1}\left(p_{i k}\right)=$ $\Delta^{-1}\left(p_{i j}\right)+\Delta^{-1}\left(p_{j k}\right)-g / 2$.

Case 6: $\quad k<j<i$. We have $p_{k i}=$ $\Delta\left(\Delta^{-1}\left(p_{k j}\right)+\Delta^{-1}\left(p_{j i}\right)-g / 2\right)$, which is equivalen- 
$\mathrm{t}$ to $\Delta^{-1}\left(p_{k i}\right)=\Delta^{-1}\left(p_{k j}\right)+\Delta^{-1}\left(p_{j i}\right)-g / 2$. Using the reciprocity property, we have $g-\Delta^{-1}\left(p_{i k}\right)=$ $g-\Delta^{-1}\left(p_{j k}\right)+g-\Delta^{-1}\left(p_{i j}\right)-g / 2$, i.e., $\Delta^{-1}\left(p_{i k}\right)=$ $\Delta^{-1}\left(p_{i j}\right)+\Delta^{-1}\left(p_{j k}\right)-g / 2$.

Considering the above six cases, we have (i) holds. This completes the proof of Lemma 1.

\section{Proof of Theorem 1}

\section{Proof.}

(1) As $c_{i k}(1)=\Delta\left(1 \times \Delta^{-1}\left(q_{i k}\right)+0 \times \Delta^{-1}\left(t_{i k}\right)\right)=$ $q_{i k}, c_{i k}(0)=\Delta\left(0 \times \Delta^{-1}\left(q_{i k}\right)+1 \times \Delta^{-1}\left(t_{i k}\right)\right)=$ $t_{i k}, i, k \in N$, we have $C(1)=Q, C(0)=T$;

(2) If $i<k$, then $c_{i k}(\alpha)=\Delta\left(\alpha \Delta^{-1}\left(l_{i k}^{+}\right)+(1-\alpha) \Delta^{-1}\left(l_{i k}^{-}\right)\right)$. Since $\Delta^{-1}\left(l_{i k}^{-}\right) \leqslant \Delta^{-1}\left(l_{i k}^{+}\right)$, then $c_{i k}(\alpha) \geqslant$ $\Delta\left(\alpha \Delta^{-1}\left(l_{i k}^{-}\right)+(1-\alpha) \Delta^{-1}\left(l_{i k}^{-}\right)\right)=l_{i k}^{-} ; c_{i k}(\alpha) \leqslant$ $\Delta\left(\alpha \Delta^{-1}\left(l_{i k}^{+}\right)+(1-\alpha) \Delta^{-1}\left(l_{i k}^{+}\right)\right)=l_{i k}^{+}$. Similarly, we can prove $c_{i k}(\alpha) \in\left[l_{i k}^{-}, l_{i k}^{+}\right]$when $i \geqslant k$.

(3) If $i<k$,

$\Delta^{-1}\left(c_{i k}(\alpha)\right)+\Delta^{-1}\left(c_{k i}(\alpha)\right)=\alpha \Delta^{-1}\left(q_{i k}\right)+(1-$ $\alpha) \Delta^{-1}\left(t_{i k}\right)+\alpha \Delta^{-1}\left(q_{k i}\right)+(1-\alpha) \Delta^{-1}\left(t_{k i}\right)=$ $\alpha \Delta^{-1}\left(l_{i k}^{+}\right)+(1-\alpha) \Delta^{-1}\left(l_{i k}^{-}\right)+\alpha \Delta^{-1}\left(l_{k i}^{-}\right)+(1-$ $\alpha) \Delta^{-1}\left(l_{k i}^{+}\right)=\alpha\left(\Delta^{-1}\left(l_{i k}^{+}\right)+\Delta^{-1}\left(l_{k i}^{-}\right)\right)+(1-$ $\alpha)\left(\Delta^{-1}\left(l_{i k}^{-}\right)+\Delta^{-1}\left(l_{k i}^{+}\right)\right)=\alpha g+(1-\alpha) g=g$.

Similarly, $\quad \Delta^{-1}\left(c_{i k}(\alpha)\right)+\Delta^{-1}\left(c_{k i}(\alpha)\right)=$ $g$, when $i \geqslant k$. And $c_{i i}(\alpha)=$ $\Delta\left(\alpha \Delta^{-1}\left(q_{i i}\right)+(1-\alpha) \Delta^{-1}\left(t_{i i}\right)\right)=g / 2, i \in N$.

Thus we can obtain that $C(\alpha)$ is a reciprocal 2tuple linguistic preference relation, $\forall \alpha \in[0,1]$. This completes the proof of Theorem 1.

\section{Proof of Theorem 2}

Proof. By Eqs. (5) and (6), we have $\Delta^{-1}\left(q_{i k}\right)=$ $\Delta^{-1}\left(q_{i j}\right)+\Delta^{-1}\left(q_{j k}\right)-g / 2 ; \Delta^{-1}\left(t_{i k}\right)=\Delta^{-1}\left(t_{i j}\right)+$ $\Delta^{-1}\left(t_{j k}\right)-g / 2$, then

$$
\begin{aligned}
c_{i k}(\alpha)= & \Delta\left(\alpha \Delta^{-1}\left(q_{i k}\right)+(1-\alpha) \Delta^{-1}\left(t_{i k}\right)\right) \\
= & \Delta\left(\alpha\left(\Delta^{-1}\left(q_{i j}\right)+\Delta^{-1}\left(q_{j k}\right)-g / 2\right)+(1-\alpha) .\right. \\
& \left.\left(\Delta^{-1}\left(t_{i j}\right)+\Delta^{-1}\left(t_{j k}\right)-g / 2\right)\right) \\
= & \Delta\left(\alpha \Delta^{-1}\left(q_{i j}\right)+(1-\alpha) \Delta^{-1}\left(t_{i j}\right)+\alpha \Delta^{-1}\left(q_{j k}\right)\right. \\
& \left.+(1-\alpha) \Delta^{-1}\left(t_{j k}\right)-g / 2\right) \\
= & \Delta\left(\Delta^{-1}\left(c_{i j}(\alpha)\right)+\Delta^{-1}\left(c_{j k}(\alpha)\right)-g / 2\right), i, j, k \in N .
\end{aligned}
$$

By the definition of additive consistent 2-tuple linguistic preference relation, $C(\alpha)(\alpha \in[0,1])$ is additive consistent, which completes the proof of Theorem 2.

\section{References}

1. S. Alonso, F.J. Cabrerizo, F. Chiclana, F. Herrera, and E. Herrera-Viedma, "Group decision making with incomplete fuzzy linguistic preference relations," International Journal of Intelligent Systems, 24, 201-222 (2009)

2. S. Alonso, F. Chiclana, F. Herrera, E. Herrera-Viedma, J. Alcalá-Fdez and C. Porcel, "A consistency-based procedure to estimate missing pairwise preference values," International Journal of Intelligent Systems, 23, 155-175 (2008)

3. S. Alonso, E. Herrera-Viedma, F. Chiclana and F. Herrera, "A web based consensus support system for group decision making problems and incomplete preferences," Information Sciences, 180, 4477-4495 (2010)

4. F.J. Cabrerizo, I.J. Pérez and E. Herrera-Viedma, "Managing the consensus in group decision making in an unbalanced fuzzy linguistic context with incomplete information," Knowledge-Based Systems, 23, 169-181 (2010)

5. S.M. Chen and L.W. Lee, "A new method for fuzzy group decision-making based on interval linguistic labels," in Proceedings of the 2010 IEEE International Conference on Systems Man and Cybernetics (SMC), 1-4 (2010)

6. F. Chiclana, E. Herrera-Viedma, S. " A note on two methods for estimating missing pairwise preference values," IEEE Transactions on Systems, Man, and Cybernetics, Part B: Cybernetics, 39, 1628-1633 (2009)

7. F. Chiclana, E. Herrera-Viedma, S. Alonso and F. Herrera, " Cardinal consistency of reciprocal preference relations: A characterization of multiplicative transitivity," IEEE Transactions on Fuzzy Systems, 17, 1423 (2009)

8. F. Chiclana, E. Herrera-Viedma, S. Alonso and F. Herrera, "A note on the estimation of missing pairwise preference values: a uninorm consistency based method," International Journal of Uncertainty, Fuzziness and Knowledge-Based Systems, 16(Supp. 2), 1932 (2008)

9. Y. Dong, Y. Xu and H. Li, "On consistency measures of linguistic preference relations," European Journal of Operational Research, 189, 430-444 (2008)

10. M. Fedrizzi and S. Giove, "Incomplete pairwise comparison and consistency optimization," European Journal of Operational Research, 183, 303-313 
(2007)

11. S. Genç, F.E. Boran, D. Akay and Z. Xu, "Interval multiplicative transitivity for consistency, missing values and priority weights of interval fuzzy preference relations," Information Sciences, 180, 48774891 (2010)

12. F. Herrera, E. Herrera-Viedma and F. Chiclana, "Multiperson decision-making based on multiplicative preference relations," European Journal of Operational Research, 129, 372-385 (2001)

13. F. Herrera, E. Herrera-Viedma and J.L. Verdegay, "Direct approach processes in group decision making using linguistic OWA operators," Fuzzy Sets and System$s$, 79, 175-190 (1996)

14. F. Herrera and L. Martínez, "A 2-tuple fuzzy linguistic representation model for computing with words," IEEE Transactions on Fuzzy Systems, 8, 746-752 (2000)

15. E. Herrera-Viedma, F. Chiclana, F. Herrera and S. Alonso, "Group decision-making model with incomplete fuzzy preference relations based on additive consistency," IEEE Transactions on Systems, Man, and Cybernetics, Part B: Cybernetics, 37, 176-189 (2007)

16. F. Liu, "Acceptable consistency analysis of interval reciprocal comparison matrices," Fuzzy Sets and Systems, 160, 2686-2700 (2009)

17. F. Liu, W.G. Zhang and J.H. Fu, "A new method of obtaining the priority weights from an interval fuzzy preference relation," Information Sciences, 185, 32$42(2012)$

18. F. Liu, W.G. Zhang and Z.X. Wang, "A goal programming model for incomplete interval multiplicative preference relations and its application in group decision-making," European Journal of Operational Research, 218, 747-754 (2012)

19. L. Martínez, L.G. Pérez and M.J. Barranco, "Incomplete preference relations to smooth out the coldstart in collaborative Recommender Systems," in Proceedings of the 28th North American Fuzzy Information Processing Society Annual Conference (NAFIPS2009), 1-6 (2009)

20. T.L. Saaty, The Analytic Hierarchy Process, New York: McGraw-Hill (1980)

21. T. Tanino, "Fuzzy preference orderings in group decision making," Fuzzy Sets and Systems, 12, 117-131 (1984)

22. J.M. Tapia García, M.J. Del Moral, M.A. Martínez and E. Herrera-Viedma, "A consensus model for group decision making problems with linguistic interval fuzzy preference relations," Expert Systems with
Applications, 39, 10022-10030 (2012)

23. Z. Wu and J. Xu, "Consensus reaching models of linguistic preference relations based on distance functions," Soft Computing, 16, 577-589 (2012)

24. M. Xia and Z. Xu, "Some issues on multiplicative consistency of interval reciprocal relations," International Journal of Information Technology \& Decision Making, 10, 1043-1065 (2011)

25. M. Xia, Z. Xu, and Z. Wang, "Multiplicative consistency-based decision support system for incomplete linguistic preference relations," International Journal of Systems Science, doi: 10.1080/00207721.2012.724112 (2012)

26. J. $\mathrm{Xu}$ and $\mathrm{Z}$. $\mathrm{Wu}$, "A maximizing consensus approach for alternative selection based on uncertain linguistic preference relations," Computers \& Industrial Engineering, 64, 999-1008 (2013)

27. Y. Xu, Q. Da and X. Liu, "Some properties of linguistic preference relation and its ranking in group decision making," Journal of Systems Engineering and Electronics, 21, 244-249 (2010)

28. Y. Xu, Q. Da and H. Wang, "A note on group decisionmaking procedure based on incomplete reciprocal relations," Soft Computing, 15, 1289-1300 (2011)

29. Z. Xu, "On compatibility of interval fuzzy preference relations," Fuzzy Optimization and Decision Making, 3, 217-225 (2004)

30. Z. Xu, "An approach to group decision making based on incomplete linguistic preference relations," International Journal of Information Technology \& Decision Making, 4, 153-160 (2005)

31. Z. $\mathrm{Xu}$, "A direct approach to group decision making with uncertain additive linguistic preference relations," Fuzzy Optimization and Decision Making, 5, 2132 (2006)

32. Z. Xu, "Incomplete linguistic preference relations and their fusion," Information Fusion, 7, 331-337 (2006)

33. Z. Xu, "Intuitionistic preference relations and their application in group decision making," Information Sciences, 177, 2363-2379 (2007)

34. Z. Xu, "A survey of preference relations," International Journal of General Systems, 36, 179-203 (2007)

35. Y. Zhang, H. Ma, B. Liu and J. Liu, "Group decision making with 2-tuple intuitionistic fuzzy linguistic preference relations," Soft Computing, 16, 1439-1446 (2012)

36. Z. Zhang and C. Guo, "A method for multi-granularity uncertain linguistic group decision making with incomplete weight information," Knowledge-Based Systems, 26, 111-119 (2012) 